\title{
Analysis Of Apple Equipment In The Product Design Thinking
}

\author{
Jun Yan ${ }^{1, a}$ \\ ${ }^{1}$ College of art and design, Wuhan Textile University, Wuhan, P. R. China \\ a 289627285@qq.com
}

Keywords: Design culture, Concept of Apple product

\begin{abstract}
As Apple products dominate the market nowadays, we can easily find the truth that we still do not give enough deep analysis on the cultural connotation of product design its own, and that our thinking on the company's design is needed to be improved, after reviewing the current products design of domestic industry. This article attempts to take Apple products as an example to explore the importance of design culture and design thinking in product design as a design tool.
\end{abstract}

\section{Introduction}

In recent years, as China's strong policy support for design-related industry, product design industry has been witnessed considerable development and there are many outstanding product designs. However, we can easily find that many of our products independently designed with our own research are often short-lived. Meanwhile, at the other side of the earth, a brand quickly dominates Chinese families, also forms its unique culture. It is the "Apple". From the early Apple desktop computer to the iPod, iPhone and then iPad products, we can identify that Apple focuses on user experience as well as the revolution in product appearance. This article analyses a range of social phenomena arising from Apple products and attempts to figure out the importance of culture and thinking elements in product design.

\section{The formation of Apple culture reflects its corporate philosophy}

Former Apple CEO, Steve Jobs, always adheres to the product design and development philosophy of "Design Aesthetic and the user experience comes first"; from iMac, iPod, iPhone to iPad, just from the name, we can see that Apple strongly pays attention to the "I" - that is, the focus on "user", which converts technology into the user's life experience by using convenient appearance and operation. From Apple series of electronic products, portable music, PC, mobile phones, tablet PCs and other products that are popular in the globe, we can figure out that Apple has created a product with the best way to reflect its design, creation and modern technology. Apple forms a cultural phenomenon rather than simple design of a stylish electronic product. From the "religious" product design culture, the importance of design innovation spirit is visible. Apple often advocates minimalist. The simple exterior lines and pure color of Apple products and good user experience they offered generate a high degree of recognition when the user firstly uses Apple products. Apple reflects high-tech electronic products in a simple and easy-to-use way, but not makes its products excessively simple. Apple products are graceful in shape and full of fun in the same time.

\section{1 "Design-oriented" enterprise culture}

In 1976, when Steve Jobs founded Apple, he said that Apple products would have unique and non-traditional thinking in design, as "Apple is to do perfect product like art," and "production for design" mentioned in $<<$ Kao Gong Ji $>>$. During the entire product development and production process, Apple only focuses on designing products rather than manufacturing products and how to 
lead trend in terms of design concept, which all constitute its corporate culture of "design is the core" [1]. Apple often spends lots of money on developing technology to realize its particular design goal, which indeed deserves our deep thinking, no matter our enterprises or the whole country. After years of exercise, Apple has formed its unique and unity style, which is not only reflected from the product itself. Its corporate decoration and corporate website design style also present its corporate design style. Apple aims to provide customers with products featuring in exquisite details and elegant interfaces, and even repeatedly demonstrate from the screws or line arrangement that we cannot see directly on the product. Therefore, we can say that Apple's design culture is a perfect mix of people with technology, with environment, with the product.

\section{2 . 2 The emotional design for users}

For Apple, the user experience brings emotional resonance already beyond the benefit created by the rational service. Through motivating consumers' emotional feelings, it will drive and promote consumers' demand for product to produce economic benefits. In any franchise stores of Apple, it will provide real products for consumers, unlike regular brand products. In this way, consumers can touch with the products directly, and this model can directly move consumers' all senses [2]. This strategy is more effective than other methods. At the same time, in the process of product using, users through the App store can find the content they interested in from the application of apple in massive resources, including music, games, news, books, etc. Through the product using, each user's emotion can be linked with the products. Product design is not only the appearance, but in the users' overall using experience. This is the requirements for the future products design under the rapid development of science and technology, and it's also a tendency for the future product design.

\section{3 . "Apple" design thinking is the humanistic value feedback}

For apple, the innovation on its products except the exquisite appearance and good operation, the most important is the integrity and stability of the design thinking, we should not only study the outstanding product design but also its internal reflection.

\section{3 . 1 Apple Design of "Zen” thoughts}

Jobs advocated the "Simple" Zen thought, and went to India and Japan carried out a period of meditation, this experience affected Apple product design. Design is the creation, is from nothing, out of thin air. Jobs used the products minimalist shape to illustrate the design idea of "less is more", as many enterprise trying to increase additional functions in existing products, Apple has spent more time in studying how to do subtraction, Apple was relying on such subtraction design method would make the products brought about far more than blindness and rigid functional superposition.

\section{3 . 2 The design concept of "symbol” in Apple Products}

A function key, can complete any command you want. Apple's iPhone product image already win support among thecustomers, not just the iPhone, by observing its history and the development of design culture on Apple products is not difficult to find, Apple products attempts to reveal the contemporary product design is gradually toward the symbolic tendency. Product changes our lives constantly, and has become one of the ways we live in the world. The emergence of various products, making various cultural outlook to materialism completely from the spirit level value, through the different way people is getting more closely linked [4], "apple" with its tiny details re-arouse the personal emotions, the deep desire and potential users desire to be inspired go with the updated products again and again, new experience is continuously satisfied in the Apple products, 
becoming the object that people pursuing. Thus, product design not only show the specific usage functions, but also has become a symbol of fashion, and then transformed a kind of spiritual needs rather than the actual function. A fashion product brings every consumer the same dream -- a better life [3].

The motivation we analyse how Apple products displaying the wisdom in our life is to arouse the passion of our designer by study its unique design culture and concept. Apple products redefine the emotion of life, organically binding technology, art, and humanity, and applying unique marketing strategy to becoming overlord of consumers, especially young user which keeps pursuing fashion. For those considerable amount of youth who chase after trends, products they needed means a way of fashion life[4]. The product has become the decorative and pretentious consumer goods, reflecting to consumers' position, and become a new fetish of market cultural. Originated from the loyalty to Apple products, fans are the loyal believer of Apple, and they find the joy of chasing after it. Then the detail functions of the products are no longer important, instead, it is a symbol, a concept. Users' needs is more physical than practical.

In general, the future development path of our product design shows that we must strengthen the ability of independent research and development, and refine the design logic. The product will become invincible finally in the fierce and competitive market.

\section{Factors affecting the beauty of Apple product design}

The characteristics of product design is reflected by the influence of different factors, such as design concept, team spirit, science and technology, market demand, market competition and other factors, are invisible influence product design embodies beauty. Apple products reflect the overall characteristics of the design of the United States, the factors affecting the design of the United States has also formed the beauty of the design of apple products. Apple Corp CEO Jobs adhere to the design aesthetic, user experience first, the design concept of Apple products to a climax of the world of electronic products. Jobs is an ambitious goal and all the minor details will closely combine executive leader model. He is on the details of the pursuit of simple operation, and the fear of the pursuit of full IT product innovation passion, formidable intuition and the grasp of talent management and deployment, are directly formed supreme Apple's product design is the key factor of formal beauty. Jobs is also good at standing in the user's point of view, thus forming a kind of user experience oriented design, to achieve product humanity and human emotion. As a result two. As a result, the factors that affect the beauty of Apple's product design can be said to be derived from its founder Jobs's passion for the pursuit of perfection and creativity. In this high-tech respected era, with constantly changing people's consumption psychology, Apple products to the user experience of materials and new processing technology, constantly with the innovation of science and technology to serve the people's lives, let the market continue to feel the courage of science and technology. With the rapid development of science and technology, make the design of Apple products are pressure, other brands of electronic products on Apple products look at fiercely as a tiger does, So Apple products is continuous technology innovation and design innovation, is the so-called "Yangtze River bring forth the new through the old to make new products constantly popular and the pursuit of. So the crystal apple design is not only with Jobs in pursuit of perfect passion and wisdom of the design team has a direct relationship, also has an indirect relationship with science and technology, the development of market demand.

\section{5 . Summary}

The beauty of the design of Apple products will be a perfect symbol of the experience 
economy era. Innovation and exploration of design beauty of Apple products from Apple Corp, depends on the design team led by Jobs's brilliant mind and superb design level, depends on the pursuit of Apple Corp to consumers as the core ideas and products for perfectionism design concept, and through scientific and technological means to achieve the desired design and natural beauty. In short, the product design should Chinese Apple product design concept for the model, more attention should be paid attention to design, design aesthetics, design aesthetics and values of application in product design, so that the design goal is not only the requirement of beautiful appearance more beautiful, to make the user experience user-friendly and easy to use, in based on the observation and understanding of the user to find Chinese product design possibilities of future development direction of the times.

\section{References}

[1] Fu Liming, Research design of industrial products, Jilin people's publishing company,2002

[2] Zhang Daoyi, on design, Shaanxi people's publishing company, 2003

[3] Liu Guanzhong, culture and design, Heilongjiang science and Technology Press,1996

[4] Ling Jiyao, art and design, Shanghai people's publishing company, 2005 